\title{
Editorial
}

Respiration 2007;74:133-135

DOI: $10.1159 / 000098819$

\section{The Heresy of One Age Becomes the Orthodoxy of the Next: What Is New about Detecting Emphysema?}

\author{
Maurizio Zompatori Tiziana Laporta \\ Scienze Radiologiche, Sezione di Diagnostica per Immagini, Department of Clinical Sciences, University of Parma, \\ Parma, Italy
}

Helen Keller's (modified) quotation exemplifies very well the change in diagnostic paradigm we are witnessing today in the evaluation of pulmonary emphysema. Emphysema, a progressive, debilitating disease characterized by alveolar destruction, affects smokers $90 \%$ of the time, but can also have a genetic cause in patients with hereditary deficiency of $\alpha_{1}$-antitrypsin. Chronic obstructive pulmonary disease (COPD), including emphysema, has been predicted to become the most common cause of death in the 21 st century.

The diagnosis of this frequent and often severe condition used to be simply based on clinical findings, lung function tests and chest x-ray but this approach only made the diagnosis of typical and advanced cases possible [1]. Today, the precise evaluation of anatomical emphysema is mainly based on high-resolution computed tomography (HRCT) and quantitative CT studies. Radiologic-pathological correlations demonstrated that low attenuation areas (LAA) on CT represent macroscopic and microscopic emphysema.

The progress of surgical and nonsurgical treatment and the increasing awareness of different diseases contributing to the development of COPD and often mimicking emphysema underline the importance of a timely and precise diagnosis. Besides, quantitative techniques

\section{KARGER}

Fax +4161306 1234

E-Mail karger@karger.ch

www.karger.com (c) 2007 S. Karger AG, Basel

$0025-7931 / 07 / 0742-0133 \$ 23.50 / 0$

Accessible online at:

www.karger.com/res have been developed in the last two decades, to evaluate the severity of parenchymal destruction and to follow up the patients [2-4]. Thoracic radiologists all around the word now face the ultimate challenge: to evaluate the bronchial remodeling, along with the emphysematous destruction [5-7].

Different approaches to the quantitative evaluation of emphysema have also been proposed, such as the subjective visual score, the percentile method, the well-known 'density mask' and finally, in the more recent years, a multiparametric analysis of the lung texture, with computer-assisted programs, evaluating simultaneously a large number of different parameters [8-11]. The density bias due to gravity (CT studies are usually performed in supine position) can be corrected and a spirometric control can be added, although not all the authors agree on the usefulness of this respiratory gating.

The modern software programs can automatically segment the lungs, perform the evaluation of the lung parenchyma, and identify, extract and measure the emphysematous lesions and the central and peripheral airways (wall thickness, wall to lumen ratio and so on). Additional analytic approaches applied to the huge data set produced by the multidetector CT devices include also the calculation of the 'hole size', by grouping together adja- 
cent emphysematous voxels into a 'hole'. The size and distribution of them can be reported and controlled in serial examinations. Sakai et al. [12] in 1994 developed an automatic method to assess the distribution of these LAA on chest CT in patients with emphysema and suggested that many small 'holes' fuse into a few larger clusters.

A quantitative evaluation of the spatial distribution of LAA on CT using texture analysis and fractal geometry in patients with emphysema was proposed by Mishima et al. $[13,14]$ a few years later. This approach could be particularly useful in revealing the pattern of progression of emphysema. LAAs were defined as the areas having a density less than the mean minus one SD of the control $(-960 \mathrm{HU})$. The authors found that increases of LAA in patients with COPD reflect the development of pathological emphysema.

The cumulative size distribution of LAA clusters follows a power law characterized by an exponent $\mathrm{D}$, which is a measure of the complexity of the terminal airspace geometry. LAA clusters tend to coalesce, forming progressively larger clusters as the weak elastic fibers separating them break under tension. The healthy lung tissue near emphysematous lesions has a high probability of suffering from emphysema in the long run. This process can transitorily leave the percentage of lung field occupied by LAAs (LAA\%) unchanged, whereas it decreases progressively the number of small clusters and increases the number of large clusters, with a resulting reduction in $\mathrm{D}$. D is considered a sensitive parameter for the early detection of the terminal airspace enlargement and the architecture simplification occurring in emphysema. In a few words, the mean size of the clusters increases with the emphysema worsening, with a simultaneous decrease in the number of clusters.
More recently, Matsuoka et al. [15] evaluated the morphological progression of emphysema on HRCT by means of the analysis of the longitudinal change in the number and size of low-attenuation clusters (LAC). They found that, on the morphological progression, the mean size of LAC was significantly increased during a follow-up period of 6 months or greater, whereas no significant correlation was found between the number of LAC and follow-up period.

The article by Matsuoka et al. [16], published in this issue of Respiration, further extends the analysis of this topic, with a detailed examination of the relationship between the number of LAC of various sizes and the progressive extent of emphysema. Their results clearly show that the degree of cluster coalescence depends on the size of clusters and the extent of emphysema. Small 'holes' tend to coalesce into larger clusters in patients with severe emphysema but the confluence of the clusters is less common in mild emphysema.

All these advancements make us think that what could be previously considered heresy by old pneumologists i.e. CT as the in vivo gold standard for the diagnosis and follow-up of the pulmonary emphysema - can now be viewed as the orthodoxy of our age.

However, the early results of the magnetic resonance studies of peripheral lung air spaces, using hyperpolarized ${ }^{3} \mathrm{He}$ and the apparent diffusion coefficient calculation, seem to suggest that the MR study has the potential to supplement and exceed the brilliant results of thoracic $\mathrm{CT}$ and to possibly become the brand-new paradigm in the foreseeable future [17-19].

\section{References}

1 Thurlbeck WM, Muller NL: Emphysema. Definition, imaging and quantification. AJR Am J Roentgenol 1994;163:1017-1025.

2 Stern EJ, Frank MS: CT of the lung in patients with pulmonary emphysema. Diagnosis, quantification and correlation with pathologic and physiologic findings. AJR Am J Roentgenol 1994;162:791-798.

3 Madani A, Keyzer C, Gevenois PA: Quantitative computed tomography assessment of lung structure and function in pulmonary emphysema. Eur Respir J 2001;18:720-730.
4 Soejima K, Yamaguchi K, Kohda E, et al: Longitudinal follow-up study of smokinginduced lung density changes by high resolution computed tomography. Am J Respir Crit Care Med 2000;161:1264-1273.

5 Nakano Y, Muro S, Sakai H, et al: Computed tomography measurements of airway dimensions and emphysema in smokers. Correlation with lung function. Am J Respir Crit Care Med 2000;162:1102-1108.

6 Aziz ZA, Wells AU, Desai SR, et al: Functional impairment in emphysema. Contribution of airway abnormalities and distribution of parenchymal disease. AJR Am J Roentgenol 2005;185:1509-1515.
7 Muller NL, Coxson H: Chronic obstructive pulmonary disease. 4 . Imaging the lungs in patients with chronic obstructive pulmonary disease. Thorax 2002;57:982-985.

8 Muller NL, Staples CA, Miller RR, et al: 'Density mask': an objective method to quantitate emphysema using computed tomography. Chest 1988;94:782-787.

9 Bankier AA, De Maertelaer V, Keyzer C, et al: Pulmonary emphysema: subjective visual grading versus objective quantification with macroscopic morphometry and thin-section CT densitometry. Radiology 1999;211:851858 
10 Uppaluri R, Mitsa T, Sanka M, et al: Quantification of pulmonary emphysema from lung computed tomography images. Am J Respir Crit Care Med 1997;156:248-254.

11 Reilly J: Using computed tomography scanning to advance understanding of chronic obstructive pulmonary disease. Proc Am Thorac Soc 2006;3:450-455.

12 Sakai N, Mishima M, Nishimura K, Itoh $H$, Kuno K: An automated method to assess the distribution of low attenuation areas on chest CT scans in chronic pulmonary emphysema patients. Chest 1994;106:13191325.
13 Mishima M, Oku Y, Kawakami K, et al: Quantitative assessment of the spatial distribution of low attenuation areas on X-ray CT using texture analysis in patients with chronic pulmonary emphysema. Front Med Biol Eng 1997;8:19-34.

14 Mishima M, Hirai T, Itoh $\mathrm{H}$, et al: Complexity of terminal airspace geometry assessed by lung computed tomography in normal subjects and patients with chronic obstructive pulmonary disease. Proc Natl Acad Sci USA 1999;96:8829-8834.

15 Matsuoka S, Kurihara Y, Yagihashi K, Nakajima Y: Morphological progression of emphysema on thin section CT. Analysis of longitudinal change in the number and size of low attenuation clusters. J Comput Assist Tomogr 2006;30:669-674.
16 Matsuoka S, Kurihara Y, Yagihashi K, Nakajima Y: Quantitative thin-section CT analysis of the enlargement and coalescence of low-attenuation clusters in patients with emphysema. Respiration 2007;74:136-141.

17 de Lange EE, Mugler JP, Brookeman JR, et al: Lung air spaces. MR imaging evaluation with hyperpolarized ${ }^{3} \mathrm{He}$ gas. Radiology 1999;210:851-857.

18 Fain SB, Panth SR, Evans MD, et al: Early emphysematous changes in asymptomatic smokers. Detection with ${ }^{3} \mathrm{He}$ MR imaging. Radiology 2006;239:875-883.

19 de Lange EE: Science to practice. What is new about detecting emphysema? Radiology 2006;239:619-620. 